\title{
Students' Perceptions of the Infrastructural Design and TA-Student Interaction Modes of a College Freshman English Tutorial Program
}

\author{
Huey-Nah Cindy Chou ${ }^{1}$, Yi-Chen Jenny Chen $^{2} \&$ Massoud Moslehpour ${ }^{3}$ \\ ${ }^{1}$ International School of Technology and Management, Feng Chia University, Taichung, Taiwan \\ ${ }^{2}$ Foreign Language Center, Providence University, Taichung, Taiwan \\ ${ }^{3}$ Department of Business Administration, Asia University, Taichung, Taiwan \\ Correspondence: Massoud Moslehpour, Department of Business Administration, Asia University, 500, Lioufeng \\ Rd., Wufeng, Taichung 41354, Taiwan. E-mail: writetodrm@gmail.com
}

\author{
Received: April 6, 2016 Accepted: April 27, 2016 Online Published: May 25, 2016 \\ doi:10.5539/ijel.v6n3p1 URL: http://dx.doi.org/10.5539/ijel.v6n3p1
}

\begin{abstract}
In recent years, higher education institutes in Taiwan are implementing tutorial programs and are recruiting student tutors/teaching assistants (TAs) in an effort to facilitate instructional effectiveness of core subjects. Undoubtedly, infrastructural design and TA quality are two vital aspects for achieving success of the tutorial programs. This study employed research methods of surveys and interviews to examine, from students' perspectives, effectiveness of a college freshman English tutorial program in terms of its implementation and its TA-student interaction. Results of the study show that, in terms of the tutorial implementation, students were generally satisfied with one-on-one tutoring and convenience of time and location. As for preferred TA-student interaction modes, the students favored collaboration with the TAs for diagnosing and verbalizing their English learning problems. In particular, the students appreciated that the TAs listened attentively to their feelings and problems. Based on the findings, implications for program design and TA training are addressed.
\end{abstract}

Keywords: college freshman English, teaching assistants, tutorials, interactive modes, Taiwan

\section{Introduction}

In recent years, the number of teaching assistants (TAs) participating in offering tutorial services in higher education is increasing for enhancing students' academic performance while releasing instructors' burden. Tutoring is an educational support system in which a tutor uses individualization to provide remediation to students or tutees for mastery learning (Merritt, 2014). Tutorial programs, which provide opportunities for learning to take place principally in one-on-one settings, have been empirically proved to be effective for meeting remedial and compensatory needs of students who are having academic difficulties (Hedrick, McGee, \& Mittag, 2000; Juel, 1996; Topping, 1996; Weigle \& Nelson, 2004).

By the same token, Taiwan's Ministry of Education (MOE) launched a University Teaching Excellence Project (UTEP) in this decade to provide necessary grants for enhancing overall quality of college instruction (Ministry of Education, 2007). Among the numerous educational aims required of the UTEP, enhancing college students' English abilities is of great prominence to answer to the world trend of globalization. Hence, universities which are granted UTEP established TA tutorial programs (TATPs) to meet students' individual English learning needs. Studies (Chang, 2006; Chou, 2009; Lai, 2001; Shen, 2008; Yu, 2008) have shown that students' perceived satisfaction with and learning effectiveness were enhanced by TATPs.

In principle, promoting students' learning effectiveness in grades, motivation, and class performance are common goals of TATPs. Therefore, TAs are often required to fulfill multiple functions by both administrative and academic authorities which include leading group discussion, language consulting, assisting in experiments in laboratories, as well as those created for remedial purposes. The fact that TAs are closer in age to their college tutees may make interaction with students different from that of classroom instructors. As what Punyanunt-Carter \& Wanger (2005) observed, undergraduate students' perceptions of communicative ways were significantly different between teachers and TAs. However, exactly what types of TA-student interaction in the TATP works more effectively in fostering student satisfaction and learning effectiveness still remain unclear and thus need to be explored. The present study was carried out to examine students' perceptions of English TA 
tutorial program (ETATP) implementation and TA-student interactive modes. In view of the purpose of this study, two research questions were addressed to guide the study:

1) What are the students' perceptions of the implementation of the ETATP?

2) What are the students' preferred interactive modes with TAs?

\section{Literature Review}

\subsection{Psychological Basis of Tutoring}

Cognitive psychology and constructivism may help shed light on the tutoring process and therefore TAs' responsibility. According to cognitive psychology, systematic interactions between a tutor and a learner are crucial for cognitive growth. From the constructivist perspective, the role of adults or tutors is central to children's or tutees' cognitive development. In the tutoring process, tutors assist tutees in understanding and solving a problem by mediating their learning experience. In Vygotsky's views (1986), Tutees' cognitive development is enhanced by cooperating and collaborating with tutors. Hence, a competent tutor is a nurturing mediator of learning by providing the intellectual scaffolding for a tutee to climb (Merritt, 2014).

\subsection{TAs' Responsibilities and Effectiveness}

In principle, TATPs are implemented to accomplish multiple goals rather than merely dealing with grades (Park, 2004). TAs' responsibilities are expected to include fostering group discussions, learning motivation, and confidence. For example, Wang (2008), using the experiences of the University of York in UK, introduced TAs' primary duties for group discussions in seminars which provided students opportunities to think and ask questions. As a result, TAs, teachers, and students organized as a collaborative learning entity and created a model for promoting students' subject learning. In the case of TAs' guiding group discussions, Wilson and Bedford (2008) suggested that TAs' communication skills are in need of enhancement in order to maintain the effectiveness of the tutoring and discussion process especially for collaborating with both teachers and students.

In addition to examining TAs' responsibilities, other studies (Colvin, 2007; Falchikov, 2001; Hedrick et al., 2000; Juel, 1996; Lai, 2001; Topping, 1996; Weigle \& Nelson, 2004) aimed to verify effects of TA tutoring on students' cognitive performance, attitudes, confidence, and TA-student relationship. In regard to English learning, TA tutoring was proved to be effective (Atksinson \& Colby, 2006; Hedrick et al., 2000; Juel, 1996; Topping, 1996; Weigle \& Nelson, 2004). For example, Hedrick et al. (2000) found that TAs provided a positive learning relationship with students to heighten self-confidence and attitude. Weigle \& Nelson (2004) listed four features that lead TA tutoring to success: (a) peer-like relationship, (b) immediate feedback such as e-mailing paper after tutoring to modify tutees' English writing, (c) tutors as supportive listeners, and (d) continuing benefit for tutees. Moreover, Topping (1996) recognized seven benefits of TA tutoring for students: (a) active, interactive and participative learning, (b) immediate feedback, (c) lower anxiety, (d) student-centered, (e) immediate cognitive gains, and application of knowledge and skill, (f) self-efficacy and motivated learning, and (g) less authoritarian.

\subsection{TA-student Interactive Modes}

In regard to interactive modes, Anderson (1997) noted three key features of the tutoring process to reach a higher quality of student learning: (a) active participation, (b) students' own self-esteem and confidence in personal knowledge, and (c) appropriate preparation by students. Colvin (2007) stressed the interactions and relationships between tutors and tutees in effectiveness tutorial programs. Ashwin (2005) summarized key interactive modes between TAs and students including: (a) explaining to the student what is not understood, (b) showing the students how to see the subject in the way that the TAs do, (c) helping students develop new perspectives in the wider context of the discipline, and (d) TAs and students exchanging different points of view. Ashwin (2006) also added that TAs perceived themselves to steer students toward what they were expected to know and to engage students in the tutoring by asking and answering questions with students admitting to TAs what they did not understand.

In terms of TA tutoring discourse, moreover, Thonus (2002) identified three phases of diagnostic, directive, and closing. Belhiah (2009) examined four dyads of American TAs and Korean students and indicated that the initiation of TAs or students in the tutorial opening phase was found to be more flexible because of the nature of students' needs and TAs' teaching philosophy. Blatchford, Russell, Bassett, Brown, \& Martin (2007) found that, when TAs devoted more time to groups of students or individuals, students interacted more positively with the TAs, actively engage themselves in the learning process, and concentrate their efforts on their studies. McLachlan \& Hagger (2010) found that drilling was the most effective way of TAs' tutoring strategies in order to sustain individual attention. Their study also showed increasing student talk in the TA tutorial programs by training TAs to lessen their tendency of being a dominant teaching figure and increase the interaction with 
students.

\subsection{TATPs in Taiwan}

In seeking exemplary TA tutorial programs, students' learning needs, program mechanisms, legislation, and recruitment system need to take into consideration. Thus, TAs in helping students fulfill various learning needs are expected of different responsibilities; for example, instructing in big classes, teaching English listening in large listening labs, leading group discussions, and conducting on-line remedial instruction. Wu \& Lee (2009) investigated students' perspectives of the TAs' effectiveness and found that the students were somewhat satisfied with TAs' effectiveness in aspects of peer coaching, cooperative learning, and teacher-student interaction. The authors emphasized that TAs' training should place an emphasis on pedagogical strategies and that unique characteristics of different courses should be considered when universities design TA programs. Lai (2001) reported that students with high language learning anxiety were able to learn without pressure in interacting with TAs, but the tutorial program did not actually raise students' English performance. Yu (2008) studied on-line remedial programs and suggested that TAs' responsibilities should include checking students' individual learning situations, guiding students to learn, and connecting between the students and their English instructors. As for tutoring lower-level students, Shen (2008) found that remedial instruction was helpful for enhancing learning in English courses. Shen also indicated that TAs could help low-motivated students to shift their negative learning anxiety towards a positive learning awareness. In contrast to the peer-like relationship in the tutoring process, Chou (2009) examined students' perceptions of TAs' instruction in English listening labs and indicated that the students preferred an authority figure when TAs were present in the listening lab. In particular, the students expressed their positive attitude toward TAs' teaching performance, well-preparedness, enthusiasm, and encouragement.

\section{Methodology}

This study employed both quantitative and qualitative research methods to explore students' perceptions of the infrastructural design and TA-student interactive modes of an English TA tutorial program (ETATP) at a university in central Taiwan. The ETATP was staffed with 13 teaching assistants whose English proficiency was equivalent to or above CEFR B2. Since its establishment in the 2008 academic year, The ETATP has served as a learning support to the freshmen English for non-majors (FENM) students. In principle, the ETATP provided the FENM students with individualized English tutorial and remedial assistance outside of the classroom. Students may register on-line to request a tutorial session at their available time for meeting either individual needs or course requirements. The ETATP scheduled most sessions at noon and in the evenings, which would be more convenient for students to attend. Each student had a 20-minute one-on-one tutoring session upon completion of online registration.

\subsection{Participants}

For collecting quantitative data, a survey questionnaire was distributed to 1500 FENM students. A total of 1318 completed questionnaires were collected with a return rate of $87.87 \%$. Among the returned questionnaires, 16 incomplete questionnaires were discarded. As a result, a total number of 1298 valid questionnaires were used for data analysis. For collecting qualitative data, five students at the lower levels of the FENM who had participated in the ETATP for at least three times prior to this study were invited to participate in this study for videotaped observations and interviews. The five participants who were majoring in management, humanities and social science, and science were given the pseudonyms of Tom, Anny, Linda, Peter and Jane in this study.

\subsection{Instruments}

\subsubsection{The Questionnaire}

The self-report questionnaire consisted of two parts. Part 1 contained six questions to elicit the participants' demographic and related information about English proficiency and FENM tutorial experience. Part 2 consisted of 39 question items regarding students' perceptions of the ETATP operational mechanism and preferred interactive modes with TAs.

First, to establish content validity of the questionnaire, nine graduate students and one professor in TEFL were invited to review the operational categories and statements. Next, to ensure construct validity, the pilot-test questionnaire was distributed in the 2009 school year to 200 sophomores who had previous ETATP experience in their freshman year with 173 valid returned questionnaires for further analysis. A principal components analysis with orthogonal rotation was conducted on the responses to derive underlying factors. As a result, the final version of the questionnaire contained 39 items on a 5-point Likert Scale.

Next, in order to examine the reliability of the questionnaire with empirical support, item analysis and 
Cronbach's Alpha internal consistency reliability were measured. Item analysis included the pilot participants' response frequencies, percentages, means and standard deviations. Based on the result, the consistency of the questionnaire was considered satisfactory with an alpha number that ranged from .77 to .96 (Gable \& Wolf, 1993): English learning habits $(\alpha=.77)$, the ETATP operational mechanism $(\alpha=.96)$, (c) perceived ETATP outcomes $(\alpha=.92)$, and (d) interactive modes between TAs and students $(\alpha=.94)$.

\subsubsection{Video Clips and Interview Question Guide}

Stimulated recalls are often employed for "prompting participants' thoughts they had while they performed a task or participated in an event" (Gass \& Mackey, 2000, p. 17). Participations' cognitive learning process which cannot be noted through observation can be tracked during the stimulated recall. In this study, stimulated recalls prompted by the video clips was used to understand in-depth the participants' perceptions about their interaction with TAs and the tutorial process. Last, semi-standardized interviews (Berg, 2009) were used in the data collection process guided by interview questions designed prior to the interviews. In this study, the semi-standardized interviews were held at the end of the semester in which face-to-face interviews were conducted. The purpose of the interview was to collect the participants' overall perceptions of TA tutoring during the semester so the participants could express any ideas or thoughts during the interviews.

\subsection{Data Collection}

Four stages of data collection were undertaken. First, five students who agreed to be videotaped of their interactions with TAs in the tutoring process were recruited. Second, questions relating to students' perceptions of interaction with TAs were devised to guide the interviews for probing the recalls. During the interviews, the participants could freely express their positive as well as negative comments and were assured that their responses would be confidential. Third, the questionnaire was administered to $1500 \mathrm{FENM}$ students at the end of the semester. Last, the five participants who were videotaped were interviewed regarding their overall perceptions of the ETATP

\subsection{Data Analysis}

\subsubsection{Quantitative Data Analysis}

The collected questionnaire responses were analyzed with descriptive statistic which describes mean scores and standard deviations of students' responses to aspects of ETATP infrastructural design and TA-student interactive modes. The average mean of the aspects was a cut-off point for determining higher or lower agreement with a statement. In addition, the Pearson's product-moment correlation method was applied to determine whether the statistical data was significantly correlated between the two aspects. In addition, strengths of the correlation of the two variables were analyzed.

\subsubsection{Qualitative Data Analysis}

This study adopted Berg's (2009) procedures of qualitative data analysis. First, the interview data were transcribed verbatim and then reviewed for understanding major themes. Second, regularities and patterns of interactive modes between TAs and students were sorted out as themes. Last, the emerged themes were developed as the analytic framework used for supplementing the quantitative results.

\section{Results}

\subsection{Demographics and Background Information}

In regard to the participants' background and demographic information, there were more females $(62.8 \%)$ than males (37.2\%). The average number of ETATP sessions the students had attended in three months prior to participating in this study was from one to three times (92.6\%) either for meeting the FENM requirement or voluntarily. In terms of English proficiency tests, over a half of the students $(60.2 \%)$ had taken at least once including GEPT, TOEIC, and TOEFL for reasons of self-evaluation, graduation, university entrance, teachers' expectations, or studying abroad. Regarding English learning habits, the FENM students in average did not build the habit of studying English weekly $(M=2.99, S D=.98)$ or participating in English learning activities periodically $(M=2.97, S D=.97)$.

\subsection{Overall Perceptions of the ETATP}

Part 2 of the questionnaire was focused on students' perceptions of the ETATP' infrastructural design and interactive modes with TAs. The students' perceptions of interactive modes with TAs received a slightly higher average mean of $3.45(S D=.59)$ than the infrastructural design $(M=3.42, S D=.57)$. It can be seen that the students' perceptions of the two aspects of the ETATP were similarly above average; i.e., the students moderately agreed with the overall design and interactive modes of the ETATP. 


\subsubsection{The Infrastructural Design}

In regard to students' perceptions of the ETATP's infrastructural design, the mean item scores ranged from 3.30 to 3.52. As for the one-on-one tutoring mode, it was noticed that the students were moderately satisfied with such an interactive mode. Similar responses were also found in the interviews. As Anny said:

One-on-one tutoring was effective in helping solve my problems immediately. If the TA had taught many students at a time, he might not have been able to focus on what I need to learn. In this one-on-one tutoring situation, I was encouraged to tell the TA my questions and ideas. I could also constantly check understanding.

Moreover, the questionnaire responses showed that the students were moderately satisfied with the ETATP's infrastructure of convenient schedule, location, and session duration. While a student, Tom, expressed concerns over the 20-minute tutoring session being too short; another student, Peter, thought "It was exactly suitable for me because I cannot absorb the content if I learned too much." In addition, regarding the ETATP's being held at noons and in the evenings; a student, Anny, felt that "I have to be a bit in a hurry after the noon ETATP session in order to attend a class immediately following the session." Yet, another student, Linda, felt that the ETATA schedule fit well in her daily routine: "I decided to come at 5 p.m. every Wednesday because I was available then. Gradually, I got used to attending the ETATP weekly and wanted to learn English in the tutoring sessions."

\subsubsection{Learning Enhancement}

In addition to satisfaction with the program's infrastructural design, the students also moderately agreed that the ETATP helped enhance their independent learning, learning confidence, and FENM performance. The students felt that their motivation for and confidence in English learning were both fostered in the ETATP. An index of heightened learning motivation was found in the response to the item regarding participating in additional extracurricular English learning activities and contests $(M=3.45, S D=1.00)$. They also agreed that the ETATP helped improve the FENM course performance $(M=3.38, S D=.87)$. The students' satisfaction with the ETATP's being helpful for improving their FENM performance could also be found in the interviews. As Linda stated, "Effectiveness of the ETATP program was something that came to me without noticing. My grades for the FENM used to be quite unstable but now I am gradually making progress." In addition to the grade improvement, Tom noticed his improvement of comprehension in the FENM class: "In the FENM class, I did not always know what the teacher was talking about. After attending the ETATP, I now can follow what the teacher is teaching although I still do not ask questions in class about the lesson content." Another student, Anny, saw that the ETATP helped lower her English learning anxiety and consequently increased understanding in English in class: "I felt more confident and understood better than before. I was less nervous before tests."

\subsection{Preferences of the TA-student Interactive Modes}

After examining the questionnaire items relating to TA-student interactive modes, it was found that Item 30 , The TAs encouraged me $(M=3.74, S D=.89)$, received the students' highest rating. The second and third highest rated items were Item 32, The TAs listened to my thoughts $(M=3.60, S D=.83)$; and Item 24, The TAs explained until I fully understood $(M=3.58, S D=.90)$. Top ranked students' preferences of interactive modes are displayed in Table 1.

Table 1. Higher ratings of the interactive modes with TAs $(N=1298)$

\begin{tabular}{clllr}
\hline Rank & Item & Statement & Mean & SD \\
\hline 1 & 30 & The TAs encouraged me. & 3.74 & .89 \\
2 & 32 & The TAs listened to my thoughts. & 3.60 & .83 \\
3 & 24 & The TAs explained until I fully understood. & 3.58 & .90 \\
4 & 22 & I liked being tutored by the same TA. & 3.49 & 1.60 \\
5 & 27 & The TAs understood my learning difficulties. & 3.49 & .90 \\
6 & 18 & The TAs guided me to find answers rather than providing the & 3.48 & .88 \\
& & answers. & & .85 \\
7 & 33 & The TAs can find my English learning problems during tutoring. & 3.48 & .87 \\
\hline
\end{tabular}

Note. The category mean was 3.45 . Item means higher than the category mean was considered as higher preferences.

Furthermore, five preferred TA-student interactive modes were expressed in the interviews: (a) checking comprehension and attention constantly, (b) listening to students attentively, (c) being friendly and humorous, (d) guiding students to verbalize individual problems, (e) sharing English learning experience. 


\subsubsection{Checking Comprehension and Attention Constantly}

The students expressed their appreciation of TAs' consistent comprehension check of their attention and reactions. As Linda mentioned, "She [TA3] often asked whether I understood. I learned better in the question-and-answer interaction. Whenever I gave a wrong answer, she would explain further." Similarly, Jane said: "I was impressed by how my TA checked understanding through questions and answers. If he had kept talking, we would not have had the interaction necessary to keep me focused." It can be seen that, based on the students' perceptions, the TAs' continual comprehension and attention check helped facilitate the students' attention and learning.

\subsubsection{Listening to Students Attentively}

The TAs did not only help students solve English learning problems, they also played the role of listener. Given the fact that the students were freshmen who were in the process of adjusting to the new university life, the ETATP provided a platform for solving and sharing both academic learning experience and personal feelings. Such a student need was clearly expressed by Tom: "She [TA1] listened caringly to me for my problems, which made me feel more willing to discuss personal feelings with her." In light of the TAs' caring responses, a warm atmosphere was created to help motivate students to participate in further tutorial sessions and in the meanwhile to continue active English learning.

\subsubsection{Being Friendly and Humorous}

Surprisingly, the TAs' personality was also considered by the students as a vital element of the effective TA-student interaction. TAs' personalities are crucial in creating an anxiety-free atmosphere for the students. Tom was impressed by his TA's humor: "TA1 was very humorous and funny so I felt relaxed in interacting with her. It was more interesting to learn in a relaxing environment than in the classroom.” Therefore, an effective means to creating a receiving atmosphere in the ETATP was TAs' friendliness and humor.

\subsubsection{Guiding Students to Verbalize Individual Problems}

In the ETATP, the students would normally prepare their own questions prior to the tutoring session. However, it was found that the students would ask further questions in the interaction with TAs. In principle, it was observed that there were two types of questions stimulated by the TA-student interaction: confirmative and probing questions. The first type of questions was for verification and confirmation. Take Jane's question as an example: "After the TA taught me the relative pronouns, I asked her why I should add a sentence behind the relative pronoun." The other type of questions was for unveiling previously unaware problems or difficulties. Linda delineated a situation when additional questions were stimulated during the tutoring process: "I asked more questions in the tutorial process. Those questions had been troubling me for a long time, but were ignored. During the tutoring process, I realized that I actually had more questions than I had prepared prior to being tutored." In brief, the students not only clarified knowledge in the ETATP but also learnt to articulate ignored problems with the TAs' guidance.

\subsubsection{Sharing English Learning Experience}

All the TAs were English-major graduates and senior undergraduates who were able to share their own academic and English learning experiences with the freshmen. Therefore, the students expected to learn from the TAs' previous English learning experience for resolving problems and barriers that they encountered in the freshman year of college. Linda pointed out how she valued TAs' learning experience: "I prefer that the TA tutored me with her own experience in learning to discern confusing grammar points."

\section{Discussion and Conclusion}

\subsection{Perceptions of the Overall ETATP Design}

Generally speaking, the students were moderately satisfied $(M=3.42)$ with the ETATP infrastructural design. Nonetheless, there is still room for improvement. The quantitative results corresponded to the interviews in that the students perceived the ETATP to be effective, especially the one-on-one tutoring and English learning enhancement. In light of the one-on-one tutoring, the students felt more at ease to ask questions and clarify understanding by interacting with the TAs. The results are consistent with previous studies that TA tutoring was an effective way for subject learning (Hedrick et al., 2000; Juel, 1996; Price et al., 2007; Schofield, 2007; Topping, 1996; Weigle \& Nelson, 2004; Wu \& Lee, 2009; Yu, 2008). In addition, extending the motivation and confidence developed in the tutoring process to autonomous English learning is in accordance with findings of previous studies (Blatchford et al., 2007; Juel, 1996). 


\subsection{Preferences of the TA-student Interactive Modes}

In light of the triangulated results, the students in this study preferred that TAs listen attentively to their problems and feelings. Such a finding corresponds to that of Ehly \& Vazquez (1998) in that TAs should be able to empathize with students' feelings and problem encountered in learning English. The students also appreciated the supportive and friendly environment of the ETATP. This finding suggests that TAs assume roles of both tutor and friend (Brown, 2007; Lai, 2001; Schofield, 2007; Topping, 1996; Weigle \& Nelson, 2004).

The students also preferred collaborating with the TAs for diagnosing and guided verbalization of their English learning problems. They found it more helpful when the TAs prompted them to construct unrecognized or further problems. Hence, this study adds to the supposition that TAs should not only focus on students' conceived questions but should also develop skills of collaboration with students to unveil unaware or ignored questions. Additional preferred interactional modes found in this and previous studies also include TAs' asking students questions to sustain concentration, checking comprehension and enhancing self-corrections (Luo et al., 2000; Twale et al., 1997), and being humorous and friendly (Anderson, 1997; Lai, 2001; Luo et al., 2001).

\section{Implications}

Findings of this study bear numerous significant implications for future TA tutorial program design. For program design, first, it is imperative for the program coordinator to meet with TAs periodically for understanding individual difficulties encountered in the tutoring process. Periodical meetings can also provide TAs with a supportive environment in which common problems and useful tutoring techniques and tips are shared. Second, students' learning needs should be briefed to the TAs in the periodical meetings and should be taken into consideration to constantly improve the ETATP quality and tutoring effectiveness. For example, one-on-one peer-like tutoring which provides individualized academic and emotional assistance was valued highly by the students in this study. The students appreciated it that the TAs listen attentively to their English learning problems and guide them step-by-step to achieve solutions to their problems. Last, the ETATP schedule should be planned at the students' convenience in order to encourage participation in the program. For example, ETATPs may be held at noon and in the evenings.

For TAs, firs of all, they should be trained to possess skills of creating rapport with students at the beginning phase. Allowing students to feel free to initiate conversations may be one of the effective ways conducive to a trusting peer-like relationship between TAs and students. TAs then can take advantages of the developed peer-like relationship for achieving a more effective tutoring outcome. Second, following the initial free talk, it may become easier for TAs to motivate students to continue attending TA tutoring and autonomous learning. Therefore, TAs may plan a series of tutoring sessions with students to systematically diagnose and solve learning problems. Third, being aware of students' responses during the entire tutoring process are vital for TAs to be able to adjust teaching pace and techniques accordingly. Hence, TAs should learn to discern students' verbal and nonverbal responses including silence, paying attention, nodding, and facial expression in order to fully understand students' learning state. Fourth, TAs should cultivate empathy for students so that they fully understand the students' cognitive and emotional barriers in learning English. According to the students' preferred interactive modes in this study, they liked to learn from the TAs' experiences. It is thus suggested that TAs develop empathic listening skills for diagnosing students' needs before providing related learning experience. Last, as indicated by the results, the students were satisfied with the TAs' guiding them to solve their own problems. As a result, the students' confidence and motivation in learning English were enhanced.

\section{Limitations and Suggestions}

Albeit insightful, this study had three limitations. First, due to the limited number of participants, results of this study may not represent all non-English major students' perceptions of the ETATP so it is suggested to use the results with caution. In addition, the questionnaires were distributed near the end of the semester for obtaining student's' overall perceptions of the ETATP. This study failed to conduct a comparative study by administering pre- and post-tests to determine progress and change of students' learning and attitudes in the ETATP.

Future research is suggested to survey TAs' perceptions toward different aspects of ETATPs and interactive modes in the future. First of all, this study explored fixed dyads of TAs and students but students may have different perceptions toward different TAs' tutoring. Therefore, it is suggested that future studies explore students' responses and interactive modes with different TAs. Second, as aforementioned, this study did not collect the students' pre- and post-tutoring perceptions. It is thus recommended to design a comparative study to discern students' perceptions before and after participating in ETATPs. Last, students' academic performance and attitude towards the freshman English course can be studied in the future to add to the overall effectiveness of the ETATP. 


\section{References}

Anderson, C. (1997). Enabling and shaping understanding through tutorials. In F. Marton, D. Hounsell, \& N. J. Entwistle (Eds.), The Experience of learning: Implications for teaching and studying in higher education (pp. 184-197). Edinburgh, UK: University of Edinburgh, Centre for Teaching, Learning and Assessment.

Ashwin, P. (2005). Variation in students' experiences of the Oxford Tutorial. Higher Education, 50, 631-644. http://dx.doi.org/10.1007/s10734-004-6369-6

Ashwin, P. (2006). Variation in academics' account of Tutorial. Studies in Higher Education, 31(6), 651-665. http://dx.doi.org/10.1080/03075070601004234

Atkinson, T., \& Colby, S. (2006). Who's teaching, who's learning? Analyzing the professional growth of $\begin{array}{lllll}\text { graduate student tutors. Mentoring \& Tutoring, } 14(2), & \text { 227-245. }\end{array}$ http://dx.doi.org/10.1080/13611260500493642

Basturkmen, H. (2003). So what happens when the tutor walks in? Some observations on interaction in a university discussion group with and without the tutor. Journal of English for Academic Purposes, 2, 21-33. http://dx.doi.org/10.1016/S1475-1585(02)00034-6

Belhiah, H. (2009). Tutoring as an embodied activity: How speech, gaze, and body orientation are coordinated to conduct ESL tutorial business. Journal of Pragmatics, 41, 829-841. http://dx.doi.org/10.1016/j.pragma.2008.09.027

Berg, B. L. (2009). Qualitative research methods (7th ed.). Boston, MA: Pearson Education.

Blatchford, P., Russell, A., Bassett, P., Brown, P., \& Martin, C. (2007). The role and effects of teaching assistants in English primary schools (Year 4 to 6) 2000-2003. Results from the class size and pupil-adult ratios (CSPAR) KS2 project. British Educational Research Journal, 33(1), 5-26. http://dx.doi.org/10.1080/01411920601104292

Bloom, B. S. (Ed.). (1956). Taxonomy of educational objectives: Handbook I, cognitive domain. New York: David McKay.

Brown, D. H. (2001). Teaching by principles: An interactive approach to language pedagogy (2nd ed.). New York: Longman.

Brown, D. H. (2007). Principles of language learning \& teaching (5th ed.). White Plains, NY: Pearson Education.

Chang, W. C. V. (2006). Promoting English proficiency at college and universities in Taiwan: Policies and strategies. Journal of Education Resources and Research, 79, 157-174.

Chen, M. L. (2006). Teaching assistants make class colorful. Evaluation Bimonthly, 3, 16-17.

Cheng, H. O., \& Lee, S. C. (2001). Development of university teaching assistant training program-A case study on the training of teaching assistant of Tamkang University calculus courses. Journal of Educational Media \& Library Sciences, 38(4), 439-452.

Chou, H. N. C. (2009). Students' perceptions of GTA instruction of the English listening lab. English Teaching \& Learning, 33(4), 35-83.

Chou, J. K. (2006). The introduction of teaching assistant program in university of Cornell of America. Retrieved from http://ctld.ntu.edu.tw/epaper/?p=12

Colvin, J. W. (2007) Peer tutoring and social dynamics in higher education. Mentoring \& Tutoring: Partnership in Learning, 15(2), 165-181. http://dx.doi.org/10.1080/13611260601086345

Duran, D., \& Monereo, C. (2005). Styles and sequence of cooperative interaction in fixed and reciprocal peer tutoring. Learning and Instruction, 15, 179-199. http://dx.doi.org/10.1016/j.learninstruc.2005.04.002

Ehly, S. W., \& Vazquez, E. G. (1998). Peer counseling. In K. J. Topping \& S. W. Ehly (Eds.), Peer-assisted learning (pp. 219-316). Mahwah, NJ: Lawrence Erlbaum Associates.

Falchikov, N. (2001). Learning together: Peer tutoring in higher education. London: Routledge Falmer. http://dx.doi.org/10.4324/9780203451496

Feinman, J. M. (1991). Teaching assistants. Journal of Legal Education, 41, 269-288.

Franck, M. R., \& Samaniego, F. A. (1981). The supervision of teaching assistants: A new use of videotape. Modern Language Journal, 65(3), 273-280. http://dx.doi.org/10.1111/j.1540-4781.1981.tb00983.x 
Gable, R. K., \& Wolf, M. B. (1993). Instrument development in the affective domain (2nd ed.). Boston, MA: Kluwer Academic Publishers. http://dx.doi.org/10.1007/978-94-011-1400-4

Gass, S. M., \& Mackey, A. (2000). Stimulated recall methodology in second language research. Mahwah, NJ: Lawrence Erlbaum Associates.

Hayton, R. (2008). Teaching politics: Graduate students as tutors. Politics, 28(3), 207-214. http://dx.doi.org/10.1111/j.1467-9256.2008.00323.x

Hedrick, W. B., McGee, P., \& Mittag, K. (2000). Pre-service teacher learning through one-on-one tutoring: Reporting perceptions through e-mail. Teaching and Teacher Education, 16, 47-63. http://dx.doi.org/10.1016/S0742-051X(99)00033-5

Heins, B., Duensing, A., Stickler, U., \& Batstone, C. (2007). Spoken interaction in online and face-to-face language tutorial. Computer Assisted Language Learning, 20(3), 279-295. http://dx.doi.org/10.1080/09588220701489440

Johnson, B., \& Christensen, L. (2008). Education research: Quantitative, qualitative, and mixed approaches (3rd ed.). Thousand Oaks, CA: Sage.

Jones, R., Garralda, A., Li, D. C. S., \& Lock, G. (2006). Interactional dynamics in on-line and face-to-face peer-tutoring sessions for second language writers. Journal of Second Language Writing, 15(1), 1-23. http://dx.doi.org/10.1016/j.jslw.2005.12.001

Juel, C. (1996). What makes literacy tutoring effective? Reading Research Quarterly, 31(3), 268-289. http://dx.doi.org/10.1598/RRQ.31.3.3

Komarraju, M. (2008). A social-cognitive approach to training teaching assistants. Teaching of Psychology, 35, 327-344. http://dx.doi.org/10.1080/00986280802374344

Lai, S. M. (2001). The effect of peer tutoring on EFL learners' academic achievement, language anxiety and attitude toward EFL learning. In Proceeding of the eighteenth Conference on English Teaching and Learning in the Republic of China. (pp. 145-155). Taipei: Crane.

Lin, K. V., Liu, J. S., Tsai, P. L., \& Wu, C. Y. (2007). Preliminary evaluation of a training program for graduate students as teaching assistants. Journal of Medical Education, 11(4), 275-283.

Liu, J. (2005). Chinese graduate teaching assistants teaching freshman composition to native English speaking students. In E. Llurda (Ed.), Non-native language teachers. Perceptions, challenges and contributions to the profession (pp. 155-177). New York: Springer. http://dx.doi.org/10.1007/0-387-24565-0_9

Lu, G. Y. (2006). The introduction of teaching assistant program in university of Virginia of America. Retrieved from http://ctld.ntu.edu.tw/epaper/?p=114

Luo, J., Bellows, L., \& Grady, M. (2000). Classroom management issues for teaching assistants. Research in Higher Education, 41(3), 353-383. http://dx.doi.org/10.1023/A:1007042911919

Luo, J., Grady, M., \& Bellows, L. (2001). Instructional issues for teaching assistants. Innovative Higher Education, 25(3), 209-230. http://dx.doi.org/10.1023/A:1007603816555

McLachlan, S., \& Hagger, M. S. (2010). Effects of an autonomy-supportive intervention on tutor behaviors in a higher education context. Teaching and Teacher Education, 26, 1204-1210. http://dx.doi.org/10.1016/j.tate.2010.01.006

Merritt, R. D. (2014). Tutoring. Tutoring—Research Starters Education, 1-7.

National Education Radio. (2007, April 17). Report on achievement of teaching assistant system at National Chi Nan University and Tung-Hai University. Retrieved from http://www.csal.fcu.edu.tw/edu/program_PlanShow.asp?PPno=24

Norris, T. (1991). Nonnative English speaking teaching assistants and students performance. Research in Higher Education, 32(4), 433-448. http://dx.doi.org/10.1007/BF00992185

Oppenheim, A. N. (1992). Questionnaire design, interviewing and attitude measurement. London, UK: Pinter Publishers.

Park, C. (2004). The graduate teaching assistant: Lessons from North American experience. Teaching in Higher Education, 9(3), 349-361. http://dx.doi.org/10.1080/1356251042000216660

Pickard, N. (1996). Out-of-class language learning strategies. ELT Journal, 52(2), 150-159. 
http://dx.doi.org/10.1093/elt/50.2.150

Price, L., Richardson, J. T. E., \& Jelfs, A. (2007). Face-to-face versus online tutoring support in distance education. Studies in Higher Education, 32(1), 1-20. http://dx.doi.org/10.1080/03075070601004366

Punyanunt-Carter, N. M., \& Wanger, T. R. (2005). Communication based emotional support different between professors and teaching assistants. Education, 125, 569-574.

Russell, A., Blatchford, P., Bassett, P., Brown, P., \& Martin, C. (2005). The views of teaching assistants in English key stage 2 classes on their role, training and satisfaction. Educational Research, 47(2), 175-189. http://dx.doi.org/10.1080/00131880500104291

Schofield, T. (2007). Student and tutor perceptions of the role of the tutor in a sixth form college. Pastoral Care in Education, 25(1), 26-32. http://dx.doi.org/10.1111/j.1468-0122.2007.00397.x

Shannon, M. D., Twale, J. D., \& Moore, S. M. (1998). TA teaching effectiveness: The impact of training and teaching experience. The Journal of Higher Education, 69(4), 441-465. http://dx.doi.org/10.2307/2649274

Shen, L. B., Tseng, C. Y., Kuo, S. W., Su, Y. J., \& Chen M. Y. (2005). A preliminary study of college students' out-of-class English learning activities. Chia Nan Annual Bulletin, 31, 464-475.

Shen, Y. M. (2008). A collaborative learning model on medical English curriculum for English teachers, teaching assistants and students. Journal of General Education, 13, 145-165.

The Ministry of Education. (2007). Teaching Excellence Development Program. Retrieved from http://www.csal.fcu.edu.tw/Edu/program_start.asp

Thonus, T. (2002). Tutor and students assessment of academic writing tutorial: What is "success"? Assessing Writing, 8, 110-134. http://dx.doi.org/10.1016/S1075-2935(03)00002-3

Topping, K. J. (1996). The effectiveness of peer tutoring in further and higher education: A typology and review of literature. Higher Education, 32, 321-345. http://dx.doi.org/10.1007/BF00138870

Twale, D. J., Shannon, D. M., \& Moore, M. S. (1997). NGTA and IGTA training and experience: Comparisons between self-ratings and undergraduate student evaluations. Innovative Higher Education, 22(1), 61-77. http://dx.doi.org/10.1023/A:1025103726202

Vygotsky, L. S. (1986). Thought and language. Cambridge, MA: MIT Press.

Wang, J. Y. (2008). The sharing of being a teaching assistant's in the university of York of the UK. Retrieved from http://ctld.ntu.edu.tw/epaper/?p=747

Weigle, S. C., \& Nelson, G. L. (2004). Novice tutors and their ESL tutees: Three case studies of tutor roles and perceptions of tutorial success. Journal of Second Language Writing, 13, 203-225. http://dx.doi.org/10.1016/j.jslw.2004.04.011

Wilson, E., \& Bedford, D. (2008). New partnerships for learning: Teachers and teaching assistants working together in schools-the way forward. Journal of Education for Teaching, 34(2), 137-150. http://dx.doi.org/10.1080/02607470801979574

Wu, C. L., \& Lee, H. (2009). An analysis of the effectiveness of teaching assistants in core courses and general education courses at college level. Taiwan Journal of General Education, 3, 67-96.

Yu, C.-F. (2008). A study on the freshman English remedial program that employs blended-teaching/learning. Soochow Journal of Foreign Languages and Literatures, 26, 1-29.

\section{Copyrights}

Copyright for this article is retained by the author(s), with first publication rights granted to the journal.

This is an open-access article distributed under the terms and conditions of the Creative Commons Attribution license (http://creativecommons.org/licenses/by/3.0/). 